\title{
E nsino Superior em Turismo e Hotelaria no Brasil: Um Estudo Exploratório
}

\section{Rivanda Meira Teixeira}

RESUMO: Estudo exploratório sobre o ensino superior em turismo/hotelaria no Brasil. Tem por objetivo analisar os diversos aspectos de funcionamento dos cursos de graduação de turismo/hotelaria, as razões para sua criação e enfoques, o currículo, os métodos de ensino, os planos de expansão, a qualidade de ensino e o relacionamento entre as universidades e as empresas.

PALAVRAS-CHAVE: ensino em turismo, qualidade da formação superior, relacionamento universidade/empresa, Brasil

ABSTRACT: This study is exploratory and approaches tourism education in Brazil. The overall objective is to analyse undergraduate courses in tourism/hospitality, looking specifically at courses structure, reason for creation and focus, curriculum, plans to expand, issues of quality and their relationship with the tourism industry

KEYWORDS: tourism education, quality in education, relationship with the tourism industry, Brazil.

\section{Introduçāo}

Este artigo aborda o ensino em turismo e tem por objetivo apresentar uma análise dos cursos superiores de turismo/hotelaria no Brasil. Como estudo exploratório, pretende contribuir proporcionando uma visão geral sobre o tópico e estimular a discussão de aspectos específicos como a estrutura e funcionamento dos cursos, as 1. Doutora em Administração pela Cranfield University. Pós-doutorada em Turismo pela Bournemouth University,
Inglaterra. Docente da Universidade Federal de Sergipe. Esse estudo foi realizado com o apoio do CNPq.

Tel.: (79) 23210 67. E-mail: rivandateixeira@yahoo.com. 
razões para a sua criação, o currículo, os métodos de ensino adotados, os planos de expansão, a qualidade de ensino e o relacionamento com a indústria do turismo.

No Brasil, de acordo com Rejowski (1996), os cursos superiores de turismo, em nível de graduação, são muito recentes e datam dos anos 70. Em 1971, surge o primeiro curso de nível superior, criado por uma instituição de ensino privado, a Faculdade de Turismo do Morumbi. Outras instituições privadas, de acordo com Trigo (1991), também criam seus cursos de turismo, a exemplo da Faculdade IberoAmericana de Letras e Ciências Humanas, em São Paulo, em 1973; da Faculdade da Cidade, nc Rio de Janeiro, em 1974 e da Faculdade Associação Educacional do Litoral Santista, em 1976, em Santos.

No âmbito universitário, afirma a autora, a Universidade de São Paulo foi a pioneira, criando o curso de turismo na Escola de Comunicações e Artes em 1973. Surgem depois outros cursos em universidades: Pontifícia Universidade Católica de Campinas, em 1974, e a Universidade Católica de Pernambuco, em 1975. O primeiro curso superior de Hoteleira foi criado pela Universidade de Caxias do Sul, em 1978, Caxias do Sul, Rio Grande do Sul.

De acordo com Ansarah e Rejowski (1994), em 1994, existiam 33 cursos superiores de turismo/hotelaria no Brasil, dos quais 29 de turismo, 2 de hotelaria e 2 em turismo e hotelaria. As autoras ainda comentam que a maioria desses cursos está em estabelecimentos privados ou em "universidades emergentes", que obtiveram autorização do CFE para se transformarem em universidades.

Conforme os dados do MEC/SESU/DEDES (2000), disponíveis na internet, o crescimento do número de cursos superiores de turismo ou de turismo e hotelaria no Brasil, tem sido significativo. Até 1998, havia 157 cursos, dos quais 119 cursos de turismo e 38 de hotelaria/ administração hoteleira. Em 1999, 39 novos cursos foram autorizados, dos quais 37 de turismo e 2 de hotelaria/administração hoteleira. Em 2000, o número voltou a crescer expressivamente, pois 88 novos cursos foram autorizados pelo MEC, dos quais 69 de turismo e 19 de hotelaria/administração hoteleira. O total informado por esse Ministério é de 284 cursos, dos quais 225 de turismo e 59 de hotelaria/ administração hoteleira.

Ao se observarem esses dados do MEC, verifica-se que $94 \%$ deles são ofertados por instituições privadas e apenas $6 \%$ por instituições públicas. Entre as públicas, cerca de $3 \%$ são federais, $2 \%$ estaduais e $1 \%$ municipal. Praticamente todos os 225 cursos de turismo são unicamente de turismo, mas cerca de $2,2 \%$ deles oferecem um combinado de turịsmo e hotelaria, e 3,5\% são de administração com habilitação em gestão de turismo. Entre os 59 cursos de hotelaria, 63\% são cursos de administração com habilitação em administração hoteleira.

Dados mais recentes da Associação Brasileira dos Dirigentes das Escolas de Turismo e Hotelaria (ABDETH), publicados na Folha de S. Paulo, em 27 de maio de 2001, mostram uma situação muito mais dramática. Segundo essa Associação, atualmente, 130 instituições oferecem cursos de hotelaria ${ }^{2}$ e 250 de turismo em todo

2. Na verdade, esse crescimento refere-se mutio mais às habilitaçōes de Hotelaria criadas no âmbito de cursos de Administração do que aos cursos de Graduação em Hotelaria. (N. do E.). o país. Em dez anos, no Brasil, o número de cursos de hotelaria em nível superior, cresceu $1.757 \%$ e o de cursos de turismo, $900 \%$ (Turismo e hotelaria necessitam..., 2001).

Este artigo será apresentado em quatro partes. Inicialmente será apresentada uma breve revisão teórica sobre o ensino em turismo; em segundo, a descrição do enfoque metodológico adotado com o tipo, o método, o instrumento e os procedimentos de coleta de dados utilizados na pesquisa. Na terceira parte, os resultados serão apresentados e, finalmente, as conclusões do estudo.

\section{Ensino em Turismo}

O estudo do turismo é uma disciplina relativamente nova, assim como é reconhecida como uma indústria vital e em crescimento. Segundo Amoah e Baum (1997), existem diversas definições para turista e turismo, e essa diversidade ocorre por causa da atuação dos diferentes setores envolvidos, todos usando definições para propósitos distintos. Existe também um debate sobre se a indústria do turismo pode ser vista como uma indústria por si mesma, em vez de ser uma atividade econômica, ligando setores através dos objetivos comuns dos seus consumidores.

Pai ¿ usses autores, a indústria do turismo é intensiva de mão-de-obra e depende, para sobrevivência e vantagem competitiva, da disponibilidade de pessoas qualificadas, capazes de operar e gerenciar o produto turístico. No entanto, por razão da diversidade dessa atividade, torna-se difícil realizar programas que atendam adequadamente a públicos tão diversos. Por sua vez, Goeldner (apud Cooper, Sheparde Westlake, 1994) comenta que o turismo é ainda uma disciplina emergente e que o ensino em turismo tem tido elevado crescimento durante os últimos 50 anos, mas seu conhecimento é ainda fragmentado.

Turismo, para Cooper e Shepard (1997), é uma indústria baseada em pessoas e na qual o toque pessoal é o mais importante fato do serviço oferecido. A qualidade dos recursos humanos é, portanto, crítica para o sucesso de empresas e de indústrias como um todo.

Cooper, Shepherd e Westlake (1994) explicam três maneiras pelas quais o estudo do turismo se tem desenvolvido como uma disciplina acadêmica: inicialmente, treinamentos específicos para o setor de viagens; depois, cursos na área de negócios; posteriormente, inserção em disciplinas tradicionais como geografia, sociologia e lingüística.

Echtner (1995a) afirma que o desenvolvimento do ensino em turismo não é tarefa fácil em função da natureza da disciplina, que é segmentada, inter e multidisciplinar, o que cria conflitos e dificulta seu entendimento. Muitas propostas foram apré: í tadas em relação à disciplina; elas variam da incorporação do turismo em áreas de estudo existentes como geografia, administração ou sociologia, ao estabelecimento de programas interdisciplinares ou, ainda, à criação de escolas específicas para o ensino em turismo. 
Comenta também a autora que a implementação de modelos dos países desenvolvidos em países em desenvolvimento pode ser de baixo custo, mas, com certeza, será dispendiosa em função da sua ineficácia. Programas do primeiro mundo são baseados em negócios, distribuição e tecnologia sofisticados que raramente estão presentes nos países do Terceiro Mundo. Fatores socioculturais e econômicos devem ser considerados para o planejamento de programas adequados às necessidades desses países. Blanton (1981) destaca que diferenças na composição e background dos estudantes, estilos de aprendizagem, atitudes em relação ao turismo, contexto do trabalho e qualificação dos professores podemafetarseriamente a utilidade do material desenvolvido em outros países. Para Linton (1987), o maior desafio dos países do Terceiro Mundo é desenvolver experiência própria e estabelecer estruturas gerenciais adequadas.

Howel e Uysal (1987) dizem que existem duas áreas básicas em que o ensino em turismo pode ser segmentada: o treinamento vocacional (vocational training) e educação profissional (professional education). A primeira se refere ao treinamento do pessoal da linha de frente, de manutenção e de apoio. O conteúdo desses cursos tende a ser pouco teórico e mais voltado para o desenvolvimento de habilidades práticas, como, por exemplo, recepcionistas, garçons, chefes de cozinha, cozinheiros, agentes de viagem, guias de turismo e outros.

A educação profissional é acadêmica por natureza e se destina para os que ocupam atividades de planejadores, gerentes, pesquisadores. Conceitos teóricos são ensinados, assim como a capacidade de interpretar, avaliar e analisar informações para a tomada de decisões tanto no setor privado como no público.

De acordo com esses autores, os países subdesenvolvidos necessitam cada vez mais de profissionais que possuam percepção holística da indústria do turismo, capazes de compreendê-lo em sua totalidade, os seus inter-relacionamentos e os seus impactos, para evitar formas de desenvolvimento do turismo inadequadas ao país.

Embora a ênfase desse tipo de educação possa variar entre as instituições,

Jenkins (1980) sugere que esses programas devem incorporar três grandes áreas de estudo. A primeira trata de um referencial analítico para a interpretação dos fluxos e tendências globais; a segunda área consideraria a análise de modelos de administração de turismoadequados para o país, e a terceira dizrespeito ao ensino de técnicas de estudos de viabilidade e avaliação dos impactos do turismo.

Echtner (1995b) acrescenta mais uma área de ensino em turismo, a do desenvolvimento de empreendedores (entrepreneurial developement). A crítica mais comum ao turismo nos países subdesenvolvidos refere-se aos impactos negativos dos empreendimentos de grande porte em relação aos seus aspectos sociais, econômicos e ambientais. Tem-se discutido que grandes empreendimentos não são tão efetivos na criação de empregos e aumento de divisas, pois existe evasão de lucros. Por outro lado, afirma a autora, as empresas locais, geralmente menores em escala, oferecem maior retorno econômico às comunidades locais.

A compreensão e a aplicação das três áreas - o treinamento vocacional, a educação profissional e o desenvolvimento de empreendedores - são fundamentais para o ensino em turismo, tanto em países desenvolvidos quanto em subdesenvolvi- dos. No entanto, afirma Echtner (1995a), esses últimos, apesar de eficientes para oferecerem educação vocacional, não têm dado a mesma importância à educação profissional e empresarial voltadas para o turismo. Existe, portanto, uma lacuna a ser preenchida nesses países para o crescimento do turismo de forma integrada e dentro de uma perspectiva a longo prazo.

Este estudo pretende contribuir para o preenchimento dessa lacuna e será direcionado para a educação profissional para o turismo.

\section{Enfoque Metodológico}

Em função dos seus objetivos, este estudo pode ser classificado como exploratório, na medida em que investigará um tópico praticamente inexplorado, que é o ensino em turismo no Brasil; e também tem características de um estudo descritivo, pois tem como objetivo primordial a descrição de variáveis, além de estabelecer relação entre si. Além disso, pretende proporcionar uma visão geral, do tipo aproximativo, sobre o tema, permitindo que hipóteses sejam mais claramente definidas (Gil, 1996)

O método de pesquisa foi a mala direta, através de questionário composto de perguntas abertas e fechadas, elaborado a partir das variáveis operacionais definidas pela experiência do pesquisador e pela discussão com professores da área. Os questionários foram encaminhados pelo correio para todos os chefes/coordenadores de cursos de turismo/ hotelaria do Brasil, de acordo com a lista do MEC/SESU (dados de 1998) e EMBRATUR.

Como a resposta inicialmente foi reduzida, foram encaminhadas cartas de follow-up. Em função do baixo número de respostas e supondo-se que muitos desses questionários se extraviavam nas próprias IES, não chegando às mãos do respondente certo, decidiu-se enviar outra vez os questionários pelo correio. Procurou-se também contatar professores através de e-mail, fax ou telefone para solicitar a adesão ao estudo ou, mesmo, solicitar o nome do chefe de departamento de universidades/ faculdades do mesmo Estado. Alguns professores preferiram responder e encaminhar suas respostas por via eletrônica. A primeira remessa de questionários fo enviada em junho de 2000 e a segunda, em setembro de 2000. Após todas as tentativas, até o mês de fevereiro 2001, foram conseguidos 40 questionários respondidos, o que correspondeu a cerca de $23 \%$ do universo. Fato considerado excelente para pesquisas realizadas através do correio.

Os respondentes desse estudo foram, na sua maioria, coordenadores de cursos, diretores de faculdades/cursos. Apenas dois deles eram professores, e um era assessor. As IES participantes são oriundas principalmente da região Sudeste, com $40 \%$ dos respondentes. Desse porcentual, 30\% são oriundos do Estado de São Paulo. Cabe destacar que no Estado do Rio de Janeiro, apesar de insistentes solicitações, apenas uma instituição respondeu ao questionário, a Veiga de Almeida. Na região Norte, apenas o Departamento de Turismo da Universidade Federal do Pará se 
dispôs a responder, enquanto a Bahia teve expressiva representação com cerca de $50 \%$ dos respondentes na região Nordeste, conforme os dados apresentados na Figura 1

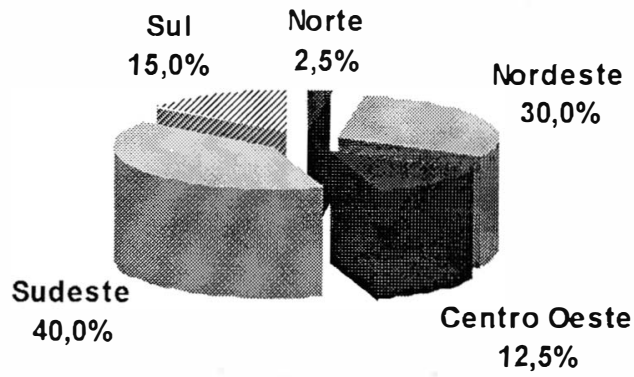

FIGURA 1 - DISTRIBUIÇÃO PORCENTUAL DA LOCALIZAÇÃO GEOGRÁFICA DAS IES

$\mathrm{Na}$ análise dos dados procurou-se adotar a combinação de enfoques qualitativos e quantitativos. Procurou-se conhecer não apenas a freqüência dos fenômenos, mas, principalmente, como esses ocorrem e quais razões que os explicam.

\section{Análise de Cursos no Brasil}

Serão abordados neste tópico todos os aspectos referentes à estrutura e ao funcionamento dos cursos, envolvendo os departamentos que os ofertam, os títulos dos cursos, a duração, o ano de início, as razões para a sua criação, os currículos, a oferta, a matrícula e admissão de alunos, as técnicas e métodos de ensino. Além disso, serão analisados os planos de expansão/modificação dos cursos, a questão da qualidade, o perfil dos alunos e dos docentes, o relacionamento com a indústria, o estágio, e finalmente é discutida a existência de cursos para formação de empreendedores e para as pequenas empresas.

\section{Departamentos/Unidades onde os cursos são ofertados}

No Brasil, a grande maioria dos cursos de turismo/hotelaria é ofertada em departamentos de turismo de acordo com a Tabela 1. Esses departamentosgeralmente estão localizados em centros de ciências humanas ou de ciências sociais.

\section{Titulos dos Cursos, Duração e Ano de Início}

As instituições de ensino superior que participaram deste estudo oferecem vários cursos na área de turismo e, na grande maioria, são cursos de bacharelado em turismo, em hotelaria ou em turismo e hotelaria. Os cursos superiores de curta duração como tecnólogo, seqüencial e politécnico são também oferecidos por algumas instituições, conforme os porcentuais apontados na tabela 2.

TABELA 1 - DISTRIBUIÇÃO PORCENTUAL DOS DEPARTAMENTOS/ UNIDADES ONDE OS CURSOS DE TURISMOIHOTELARIA SÃO OFERECIDOS

\begin{tabular}{l|c|c|}
\hline Departamento/Unidade & $\begin{array}{c}\text { Frequeéncia } \\
\text { Absoluta }\end{array}$ & $\begin{array}{c}\text { Freqüéncia } \\
\text { Relativa }\end{array}$ \\
\hline Turismo e Turismo /Hotelaria & 30 & 75,0 \\
Administração & 4 & 10,0 \\
História e Geografia & 2 & 5,0 \\
Comunicação Social & 2 & 5,0 \\
Artes, Comunicação e Turismo & 1 & 2,5 \\
Juridica e Administrativa & 1 & 2,5 \\
\hline TOTAL & 40 & 100,0 \\
\hline
\end{tabular}

TABELA 2- DISTRIBUIÇÃO PORCENTUAL DOS CURSOS OFERECIDOS PELAS IES

\begin{tabular}{l|c|c}
\hline \multicolumn{1}{|c|}{ Cursos } & $\begin{array}{c}\text { Freqüéncia- } \\
\text { Absoluta }\end{array}$ & $\begin{array}{c}\text { Frequiéncia- } \\
\text { Relativa }\end{array}$ \\
\hline Turismo & 33 & 58,9 \\
Hotelaria/Adm Hoteleira & 5 & 8,9 \\
Turismo e Hotelaria/ Administração Hoteleira & 3 & 5,4 \\
Administração com habilitação em Adm Hoteleira & 2 & 3,8 \\
Administração em Turismo & 1 & 1,7 \\
Turismo, planejamento e gestão turistica/ hoteleira & 1 & 1,7 \\
Tecnólogo/ Sequencial/ Politécnico & 9 & 16,0 \\
(turismo/administração hoteleira/ alimentos e & & \\
bebidas/ turismo e meio ambiente) & 1 & 1,7 \\
Gustronomia & 1 & 1,7 \\
Lazer e Eventos & 56 & 100,0 \\
\hline TOTAL & & \\
\hline
\end{tabular}

Obs.: A questão admitiu mais de uma resposta. 
Observou-se também que $17,5 \%$ das IES brasileiras, que participaram deste estudo, oferecem cursos de pós graduação lato sensu como gestão de empreendimentos turísticos, gestão de negócios turísticos e hoteleiros, ecoturismo, ecologia e turismo, magistério superior em turismo, gestão de empreendimentos turísticos, marketing e turismo, e cursos stricto sensu como o mestrado em administração de empresas turísticas.

Quanto à duração dos cursos de graduação nas instituições analisadas, podese observar que $64,3 \%$ deles têm duração de quatro anos, apesar de existirem cursos de três anos, de três anos e meio e de cinco anos. A Figura 2 indica os porcentuais de duração desses cursos. Os de um ano e dois anos são cursos de tecnólogo, seqüencial ou técnico. De acordo com as Diretrizes Curriculares, propostas pelo MEC, o curso de tecnólogo deve ter duração mínima de dois anos e o de bacharelado de quatro anos.

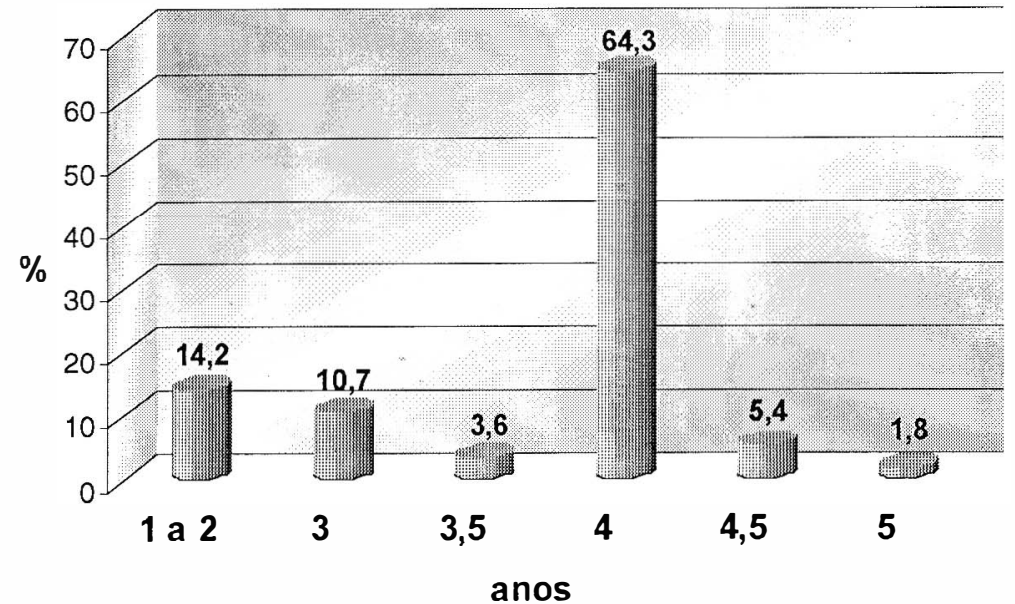

Obs.: A questão admitiu mais de uma resposta.

\section{FIGURA 2 - DISTRIBUIÇĀO PORCENTUAL DO PERIODO DE DURAÇĀO DOS} CURSOS

Pode-se constatar que os cursos de turismo/hotelaria são muito recentes no Brasil, 72,2\% dos cursos foram iniciados na década de 1990. Cabe destacar que $35 \%$ dos cursos foram criados em 1998 (Figura 3). Uma vez que os primeiros cursos de turismo/hotelaria no Brasil se iniciaram na década de 1970, logo se observa que na década de 1980 não houve grande interesse na criação de outros cursos.

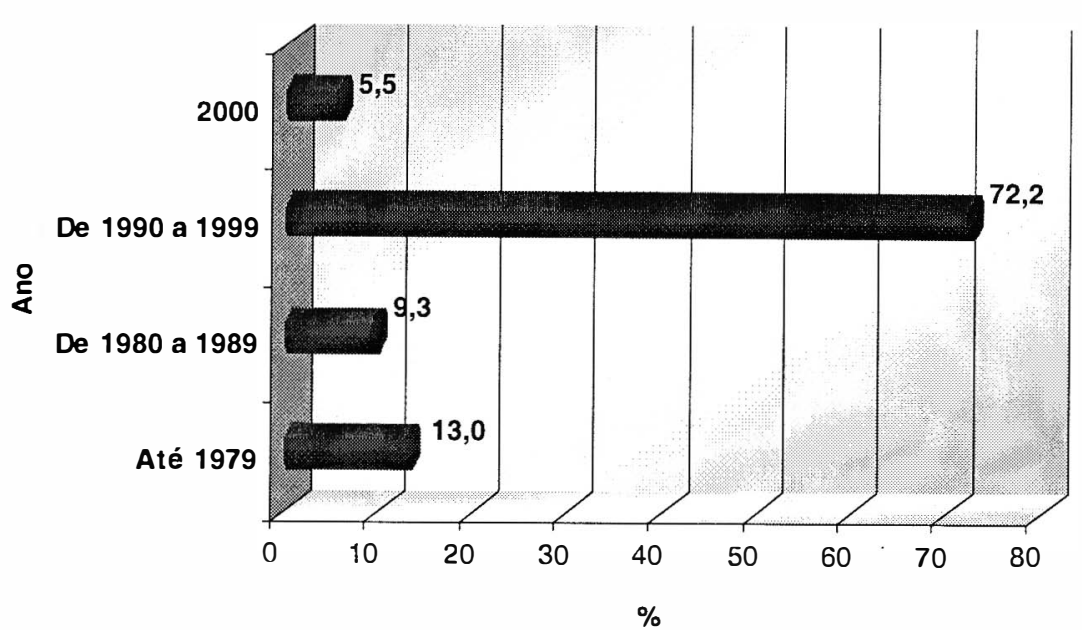

Obs.: A questão admitiu mais de uma resposta. Não havia a data de início em dois cursos.

\section{FIGURA 3 - DISTRIBUIÇĀO PORCENTUAL DO ANO DE INICIO DOS CURSOS} DE TURISMO/HOTELARIA

\section{Razões para a Criação de Cursos}

Procurou-se descobrir as razões que explicam a criação dos cursos nas instituições pesquisadas. Com $80 \%$ das respostas, a existência de demanda surge como a principal razão para a oferta de cursos de turismo/hotelaria no Brasil. No entanto, essa demanda foi explicada de várias formas. Existe a demanda em função da percepção do potencial do mercado, onde a IES já existe e sabe do potencial da oferta de novos cursos para atrair novos alunos. Essa situação é muito comum, pois as instituições que oferecem cursos de turismo/hotelaria são quase sempre privadas e estão constantemente em busca de novos alunos. Sabe-se também que os cursos de turismo/hotelaria ${ }^{3}$ são de pequeno investimento e de grande apelo para atrair

3. Na verdade, para abertura e reconhecimento de cursos superiores de Turismo e de Hotelaria no Brasil, atualmente é exigido um número mínimo de laboratórios implantados e equipados, acervo bibliográfico específico na área, e corpo docente com formaçăo e experiência na área, além de outros criterios. Pode-se verificar, assim, que os cursos de Turismo. Já as habilitacōes de Administraço voltades ao Turismo e Hotelaria podem ser consideradas como as que requerem menor investimento. (N. do E.). 
novos alunos, e muitos cursos foram criados para aproveitar a "novidade". O comentário abaixo permite entender melhor o pensamento dos respondentes:

Quando iniciei as pesquisas para elaborar o projeto de curso, em 1996, só havia uma faculdade de turismo, privada e outra de administração hoteleira, no nivel técnico, pública, para uma grande demanda. Em 1997 foram 1915 candidatos para 200 vagas anuais.

Outra forma de demanda é explicada a partir das potencialidades turísticas de uma região, onde se percebe crescente necessidade de mão-de-obra. Esse é o caso da criação de cursos em localidades com forte vocação turística, a exemplo de Foz do Iguaçu, Salvador, entre outras. Nessasregiões, existe grande facilidade de vender esses cursos pois os alunos acreditam que existem empregos disponíveis. Algumas das respostas dadas podem explicar esse enfoque:

A razão principal da criação do curso em Canela foi a de que a Região das Hortências como principal pólo turístico do RS, seria um excelente campo de atuação durante o curso para os alunos.

Demanda crescente dado o descontrole da exploração ecológica e do turismo de pesca no pantanal sul-matogrossense.

Potencial de desenvolvimento do turismo no Estado; falta de curso superior na área. Falta de visão administrativa voltada para o turismo em grande número de empreendimentos turisticos. Carência de profissionais capazes de planejar, organizar, dirigir, divulgar, planejar e controlar idéias e açōes

Existem outras formas de demanda mais específicas comoé o caso de IES que criaram cursos para formar professores em virtude da carência de docentes qualificados na área. Outras razões foram apontadas para a criação dos cursos, como a indicação da reitoria, pedido de empresários, crescimento da rede hoteleira e, finalmente, continuação do curso de tecnólogo, pois o mercado não reconhecia esse profissional e demandava outro com formação plena.

\section{Currículo}

A partir de discussões iniciadas em 1977 o MEC/SESU estabeleceu propostas de diretrizes curriculares para diversos cursos, entre eles o de turismo e hotelaria Essas diretrizes vêm sendo utilizadas pelas IES para definir seus currículos ou orientar reformas curriculares.
Os currículos das IES que participaram desse estudo foram definidos de diversas formas. Cerca de 30\% basearam-se nas necessidades de mercado através de pesquisas formais e informais, $32,5 \%$ na experiência dos seus docentes, e cerca de $30 \%$ afirmam ter utilizado as duas formas. Outros mencionam que observaram os currículos de outras faculdades de maior prestígio, ou que contrataram consultoria externa, ou que seguiram as diretrizes curriculares do MEC ou definiram o seu currículo em função da estratégia/missão da instituição.

\section{Sistema de Créditos, Matrícula e Admissão de Alunos}

As Diretrizes Curriculares do MEC sugerem que a estrutura dos cursos superiores seja definida dentro de módulos (pacotes fechados) nas formas seriada anual, seriada semestral e modular.

Apesar de 55\% dos cursos de turismo/hotelaria, que participaram desse estudo, adotarem o sistema seriado (anual ou semestral), cerca de $43 \%$ adotam o sistema de créditos, e apenas uma diz adotar os dois sistemas, possivelmente cada um para um curso diferente.

A relação candidato por vaga oferecida varia muito entre as instituições no Brasil. Existem aquelas em que a relação é de um candidato para uma vaga e aquela que pode chegar a cinqüenta candidatos para uma vaga (em uma universidade estadual que participou desse estudo). Como esperado, a maior relação candidato por vaga é encontrada nas universidades públicas; entretanto, existem universidades particulares, em que a relação pode chegar a até dez candidatos para uma vaga.

De acordo com a grande maioria dos respondentes, a situação é ainda promissora em relação ao preenchimento das vagas oferecidas pelas IES nos cursos de turismo/hotelaria no Brasil, pois em 72,5\% dessescursos a relação aluno por vaga vem aumentando nos últimos dois anos, $25 \%$ permaneceu estável e em apenas $2,5 \%$ delas essa relação vem diminuindo (Figura 4).

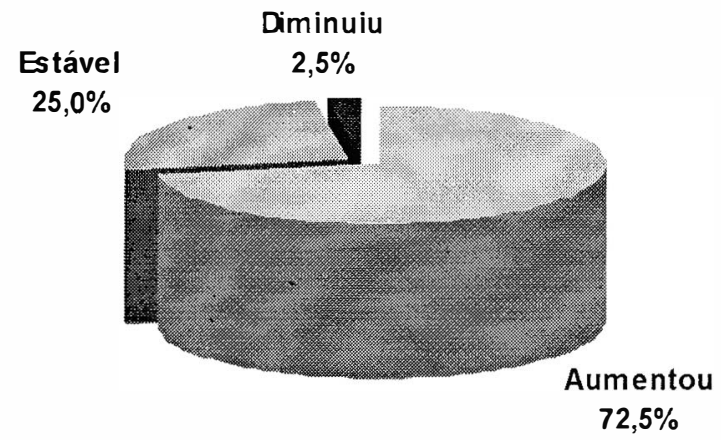

FIGURA 4 - DISTRIBUIÇÃO PORCENTUAL DA RELAÇÃO NÚMERO DE CANDIDATOS POR VAGAS 


\section{Técnicas e Métodos de Ensino}

Além dos métodos tradicionais de ensino, como aulas expositivas, pesquisa bibliográfica e seminários, os respondentes citaram as viagens/ visitas técnicas, as dinâmicas de grupo, o uso de vídeos, os filmes e palestras, os estudos de caso, a realização de pesquisas e de projetos e a monografia de conclusão de curso. Apenas duas IES mencionaram a utilização da informática como instrumental de ensino. Uma delas mencionou o uso de softwares específicos; e a outra, o acesso à Internet. Foi mencionada também a utilização de hotel-escola para as aulas práticas.

Quando perguntados se consideravam as suas técnicas de ensino adequadas ao curso, $95 \%$ dos respondentes afirmaram que sim, porque existia uma preocupação no uso de métodos que propiciassem uma visão prática da realidade. No entanto, alguns respondentes, mesmo afirmando que sim, também consideram que se necessita intensificar a parte prática do curso e de oferecer maior número de estudos decaso e maior número de vivências externas. Foi comentado queo maior obstáculo a essa prática é a carência de recursos financeiros. Além disso, outras dificuldades foram mencionadas como, por exemplo, a falta de apoio de iniciativa pública em alguns municípios, a falta de parcerias técnicas e operacionais e o insuficiente comprometimento dos alunos pelo curso.

Perguntados se consideravam seus métodos/técnicas de ensino inovadores, $80 \%$ dos que participaram deste estudo responderam que sim, $17,5 \%$ que não e $2,5 \%$ que não tinham como comparar, portanto não saberiam opinar. Dentre os métodos inovadores mencionados pelos respondentes, cabe destacar o envolvimento de alunos em pesquisas, a realização de trabalhos interdisciplinares, a participação em estágios internacionais, a participação de alunos em empresas juniores, a criação de agência de turismo no campus, palestras sobre o mercado de trabalho, trabalhos de extensão, relatórios de visitas técnicas e monografias com produção de material gráfico ou audiovisual.

Procurou-se conhecer também quantos computadores estavam disponíveis para os alunos, além da existência de revistas e periódicos para consulta na biblioteca. Alguns dos respondentes não apresentaram esses dados e mencionaram a existência, na sua instituição, de laboratórios de informática sem citar quantos computadores em cada um deles. Dos $55 \%$ que responderam, pode-se verificar que $32 \%$ possuem até cinco alunos para cada computador, enquanto $36 \%$ têm de seis a dez alunos por computador; os demais contam com mais de dez alunos para cada computador. Quanto a revistas e periódicos da área, os números parecem muito modestos, pois entre os respondentes apenas $20 \%$ afirmaram possuir mais de dez revistas ou periódicos no seu acervo para consultas.

\section{Planos de Expansāo e Modificaçāo dos Cursos}

Com o objetivo de analisar as perspectivas dos cursos em pauta, procurouse observar se o número de alunos nos últimos três anos tinha aumentado, permane- cido estável ou diminuído nas instituições pesquisadas. O porcentual do número de alunos nos cursos parece promissora, conforme indicado na Figura 4, pois em 72,5\% das instituições pesquisadas o número de alunos aumentou, em $25 \%$ permaneceu estável e somente em $2,5 \%$ diminuiu.

Entre as razões citadas pelos respondentes para explicar esse aumento de alunos, destacam-se a melhoria da qualidade do curso, o seu reconhecimento pela comunidade, a percepção dos alunos de que o mercado de turismo vem crescendo no Brasil e a criação do turno diurno. Para explicar a redução de alunos, foi mencionada a questão financeira, que é percebida pela alta inadimplência, na faixa de $20 \%$ a $30 \%$.

Procurou-se identificar também se as instituições que participaram do estudo tinham a intenção de criar cursos na área. As IES pesquisadas estão interessadas em ampliar as suas ações com grande diversidade de tipos de cursos, com preferência para curso de extensão/ pós-graduação ou novos cursos de graduação, conforme os dados apresentados na Tabela 3.

\section{TABELA 3- DISTRIBUIÇÃO PORCENTUAL DE CURSOS QUE AS} INSTITUIÇŌES PRETENDEM CRIAR

\begin{tabular}{l|c|c}
\hline \multicolumn{1}{c|}{ Cursos } & $\begin{array}{c}\text { Frequéncia- } \\
\text { Absoluta }\end{array}$ & $\begin{array}{c}\text { Frequééncia- } \\
\text { Relativa }\end{array}$ \\
\hline Extensão/Pós-graduação lato sensu & 13 & 32,5 \\
Cursos de graduação (Turismo/Hotelaria/ & 11 & 27,5 \\
Gastronomia/ Gestão e Lazer) & 6 & 15,0 \\
Cursos Seqüenciais & 6 & 15,0 \\
Curso Técnico (Guia Turistico/ Hotelaria/ Lazer) & 4 & 10,0 \\
Mestrado & 3 & 7,5 \\
Educação à distância & 1 & 2,5 \\
Doutorado & 44 & - \\
\hline TOTAL DE RESPOSTAS & 40 & 100,0 \\
\hline TOTAL DE RESPONDENTES & & \\
\hline ObS.: A questão admitiu mais de uma resposta.
\end{tabular}

Obs.: A questáo admitiu mais de uma resposta.

As frequêencias relativas foram calculadas com base no número de respondentes: 40 .

Em relação à existência de planos para modificar os cursos existentes, observou-se que $55 \%$ dessas IES pretendem fazer modificações, enquanto as restantes $45 \%$ não têm a mesma intenção. Dentre as modificações citadas, pode-se destacar a atualização do projeto pedagógico e as atualizações curriculares baseadas 
nas Diretrizes Curriculares do MEC ou para atender às necessidades do mercado. Foram mencionadas também alterações na carga horária, implantação de nível básico comum e criação de opções de terminalidade e na duração do curso de três para quatro anos.

\section{Qualidade de Ensino}

Um dos objetivos deste estudo foi analisar como as IES gerenciavam as questões relativas à qualidade dos cursos de graduação em turismo/hotelaria. Procurou-se identificar como as IES fazem o acompanhamento e implementação de instrumentos que permitam o diagnóstico dos problemas referentes à qualidade dos seus cursos.

De acordo com os respondentes, a qualidade dos cursos é prioridade, e apenas um deles apresentou uma perspectiva negativa ao afirmar que a instituição onde trabalhava não valorizava o curso e não investia em qualidade. Para facilitar o entendimento dessas percepções, as respostas foram agrupadas em categorias, que são apresentadas na Tabela 4

\section{TABELA 4 - DISTRIBUIÇÃO PORCENTUAL DAS FORMAS DE}

\section{GERENCIAMENTO DE QUALIDADE}

\begin{tabular}{l|c|c}
\hline Categorias & $\begin{array}{c}\text { Freque éncia- } \\
\text { Absoluta }\end{array}$ & $\begin{array}{c}\text { Frequééncia- } \\
\text { Relativa }\end{array}$ \\
\hline Investimento em docentes (qualificação/ & 12 & 30,0 \\
atualização/ contratação) & 7 & 17,5 \\
Com preocupação/ não respondeu diretamente & 7 & 17,5 \\
Busca permanente/continua & 7 & 17,5 \\
Politica de qualidade/ Avaliação Institucional & 6 & 15,0 \\
Inovação métodos de ensino/ projeto & 4 & 10,0 \\
pedagógico/ atualização do curriculo & 1 & 2,5 \\
Biblioteca/laboratórios/hotel escola/ empresa & 44 & - \\
júnior & 40 & 100,0 \\
Não investe em qualidade & & \\
\hline TOTAL DE RESPOSTAS & & \\
\hline TOTAL DE RESPONDENTES & & \\
\hline
\end{tabular}

Obs.: A questão admitiu mais de uma resposta.

As freqüências relativas foram calculadas com base no número de respondentes: 40 .
Procurou-se também investigar especificamente quais as formas de controle de qualidade adotadas nos cursos. As respostas foram agrupadas e estão relacionadas na Tabela 5 .

TABELA 5 - DISTRIBUIÇÃO PORCENTUAL DAS FORMAS DE CONTROLE DE QUALIDADE

\begin{tabular}{l|c|c}
\hline \multicolumn{1}{|c|}{ Formas de controle } & $\begin{array}{c}\text { Freqüéncia- } \\
\text { Absoluta }\end{array}$ & $\begin{array}{c}\text { Frequééncia- } \\
\text { Relativa }\end{array}$ \\
\hline Avaliação dos professores pelos alunos & 37 & 92.5 \\
$\begin{array}{l}\text { Avaliação institucional/ coordenação de } \\
\text { qualidade/ programa de qualidade }\end{array}$ & 11 & 27.5 \\
$\begin{array}{l}\text { Não é sistematizada/ baseada em } \\
\text { observaçōes/subjetiva }\end{array}$ & 7 & 17.5 \\
Pesquisa de egressos & 4 & 10.0 \\
Avaliação extema & 4 & 10.0 \\
Em processo de elaboração & 2 & 5.0 \\
Através de reuniões com alunos/ docentes & 4 & 10.0 \\
\hline TOTAL DE RESPOSTAS & 69 & - \\
\hline TOTAL DE RESPONDENTES & 40 & 100 \\
\hline
\end{tabular}

Obs.: A questão admitiu mais de uma resposta.

As freqüências relativas foram calculadas com base no número

de respondentes: 40.

Como pode ser observado, a avaliação dos professores pelos alunos é prática comum nas IES que participaram desse estudo. Essa avaliação, segundo os respondentes, pode ser realizada de várias formas: semestral, anual, através de questionários, amostra, em reuniões ou informal. Para alguns, essa avaliação é mais ampla e é chamada avaliação institucional, em que não só os professores são avaliados, mas a instituição como um todo (laboratórios, biblioteca e serviços). Apenas 10\% mencionam realizar avaliações externas em que representantes do setor ou professores de fora fazem uma avaliação.

Procurou-se verificar se as instituições realizavam o acompanhamento dos seus egressos. Apenas $10 \%$ das instituições pesquisadas dizem realizar pesquisa de acompanhamento com os egressos, 55\% não realizam, porque ainda não têm alunos graduados, e as restantes não fazem. Algumas comentam que, apesar de não terem acompanhamento sistemático dos egressos, o número de alunos que trabalham em empresas privadas é sempre superior ao do setor público e que este porcentual varia 
de $15 \%$ a $60 \%$. Uma delas comentou que $22 \%$ dos alunos do $5^{\circ}$ período já estavam trabalhando na área.

\section{Perfil dos Alunos}

Apesar de os cursos de graduação em turismo/hotelaria serem recentes, visto que a maioria dos respondentes iniciou suas atividades no final dos anos 1990, o número de alunos freqüentadores desses cursos é alto. É interessante mencionar que três das institutições pesquisadas têm mais de mil alunos, estando portanto na faixa de mais de 500. (Figura 5).

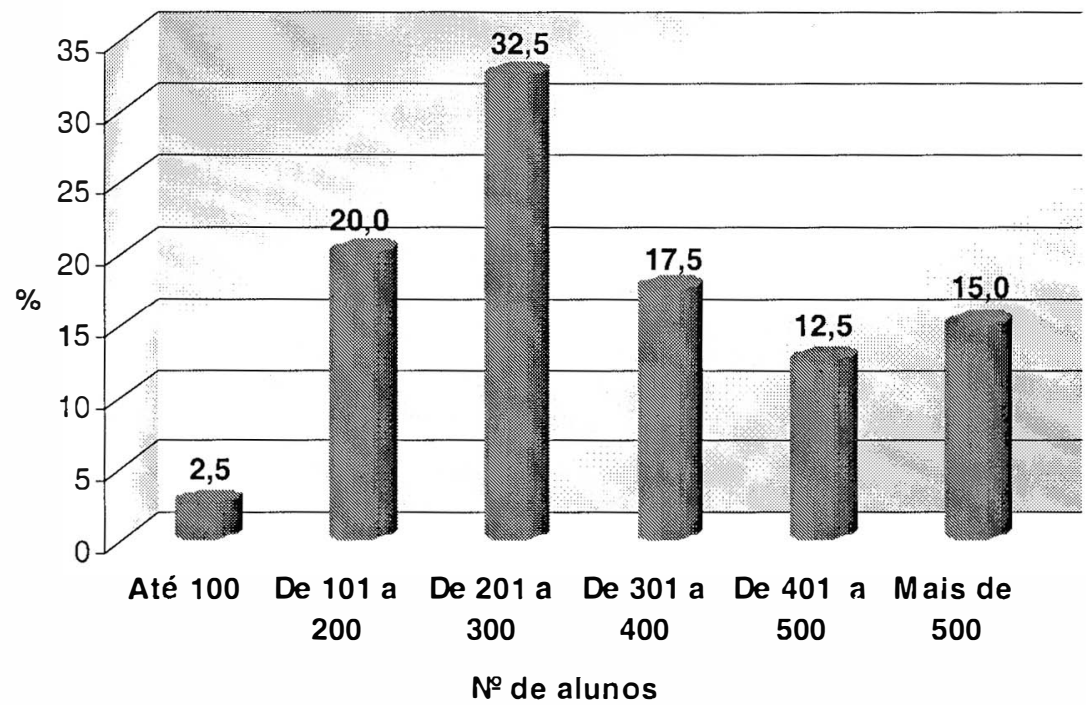

\section{FIGURA 5 - DISTRIBUIÇÃO PORCENTUAL DO NÚMERO DE ALUNOS} FREQÜENTANDO OS CURSOS

A Figura 6 indica que o número de graduados também é elevado, pois dentre os $50 \%$ que responderam (os $50 \%$ restantes não sabiam ou não tinham alunos graduados), $30 \%$ têm mais de 500 alunos que já concluíram os cursos, e 15\% mencionaram números acima de mil.

Ao analisar a Figura 7, pode-seobservarque os alunos freqüentadores desses cursos são predominantemente femininos, pois, de acordo com os respondentes dessa questão, verifica-se que em $94,2 \%$ das instituições predominam os alunos do sexo feminino nas faixas maiores de $50 \%$.

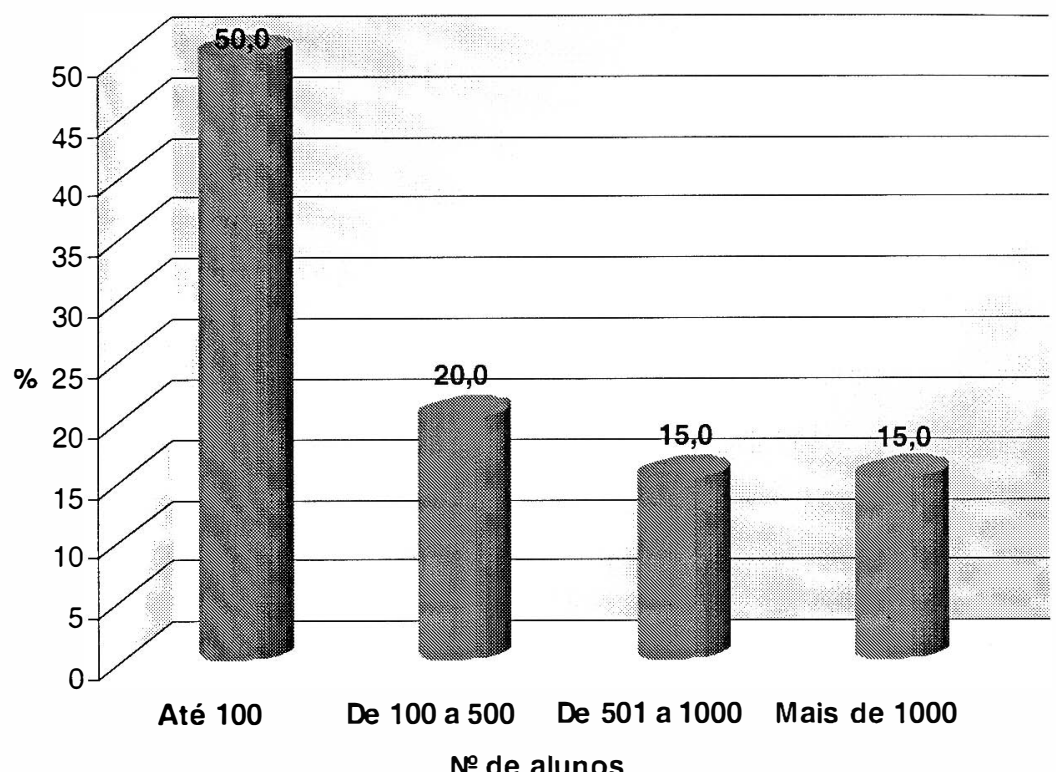

FIGURA 6 - DISTRIBUIÇÃO PORCENTUAL DE ALUNOS GRADUADOS

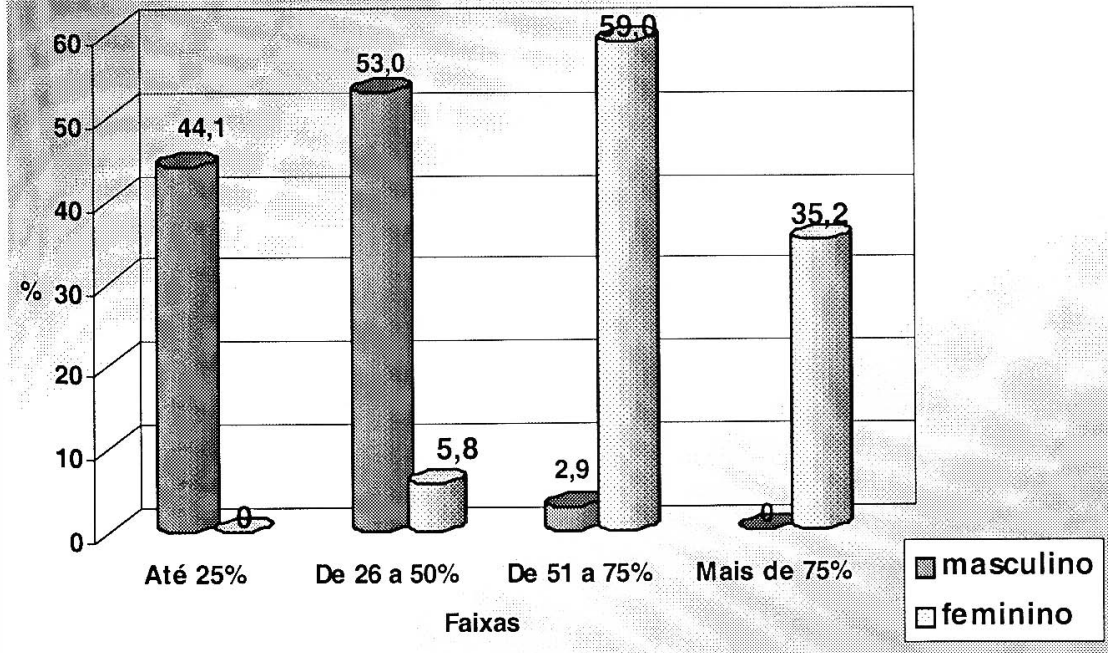

FIGURA 7 - DISTRIBUIÇÃO PORCENTUAL DE ALUNOS EM RELAÇÃO AO SEXO 
Os alunos que cursam turismo/hotelaria na sua maioria estudam e trabalham. Entre os que responderam a essa questão, $70,8 \%$ estão na faixa de mais de $50 \%$ dos alunos que estudam e trabalham contra $16 \%$ na mesma faixa dos que só estudam (Figurit 8).

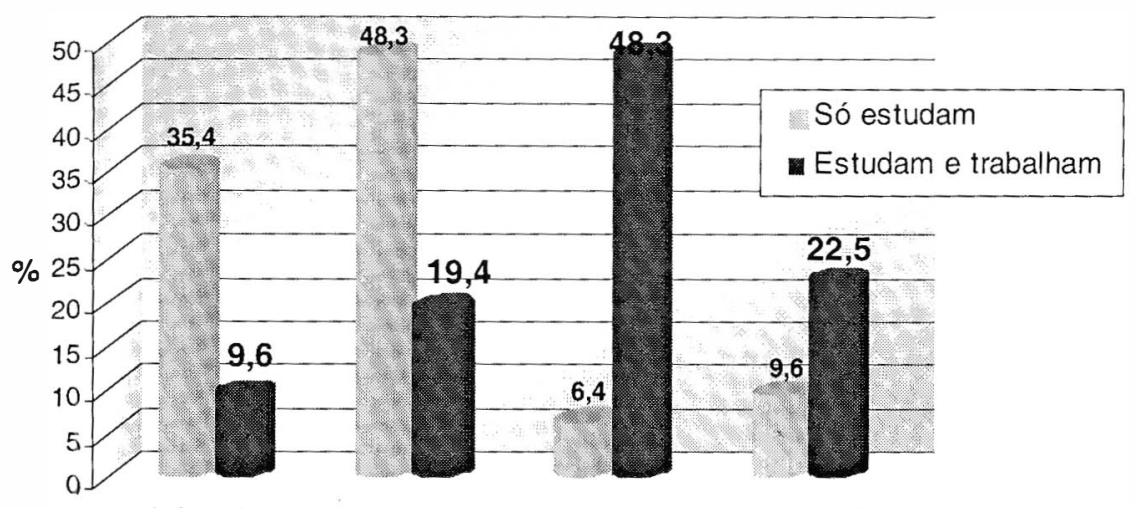

Até $25 \%$ De 26 a $50 \%$ De 51 a $75 \%$ Mais de $75 \%$

Faixas

\section{FIGURA 8 - DISTRIBUICCÃO PORCENTUAL DOS ALUNOS QUE SÓ ESTUDAM} E DOS QUE ESTUDAM E TRABALHAM

\section{Perfil dos Docentes}

Inicialmente procurou-se observar quantos professores trabalhavam nos departamentos de turismo/hotelaria das instituições que participaram do estudo. Ao observar a figura 9 , nota-se que $46 \%$ das instituições possuem de 11 a 20 docentes nos seus quadros. Uma das instituições declarou possuir 61 docentes no seus cursos de turismo e de hotelaria com 1.429 alunos.

A grande maioria trabalha nessas instituições em tempo parcial, com vinte ou quarenta horas ou no regime de horista. Apenas duas das instituições que responderam a essa questão têm mais de $20 \%$ de seus professores em regime de dedicação exclusiva.

Identificou-se que a formação acadêmica (background) dos professores dos cursos de turismo/ hotelaria é muito heterogênea, pois foram mencionadas 27 formações diferenciadas. As mais destacadas, em ordem de apresentação, foram turismo, administração, geografia e história. Em seguida foram citadas sociologia, letras (português, inglês, espanhol), economia, psicologia, informática, administração hoteleira e direito.

Para que o profissional de turismo/hotelaria seja competente no exercício da sua profissão, é necessário que sua formação contemple tanto os aspectos teóricos como os práticos. Com o objetivo de conhecer como essa equação se concretizava, interrogou-se a respeito do percentual dos docentes que tinham experiência prática na área. Segundos os dados indicados na figura 10, o número de docentes, que já trabalharam especificamente na área, é relativamente baixo, pois $69 \%$ dos que responderam a essa questão afirmam que somente até $50 \%$ dos docentes têm experiência prática em turismo/hotelaria.

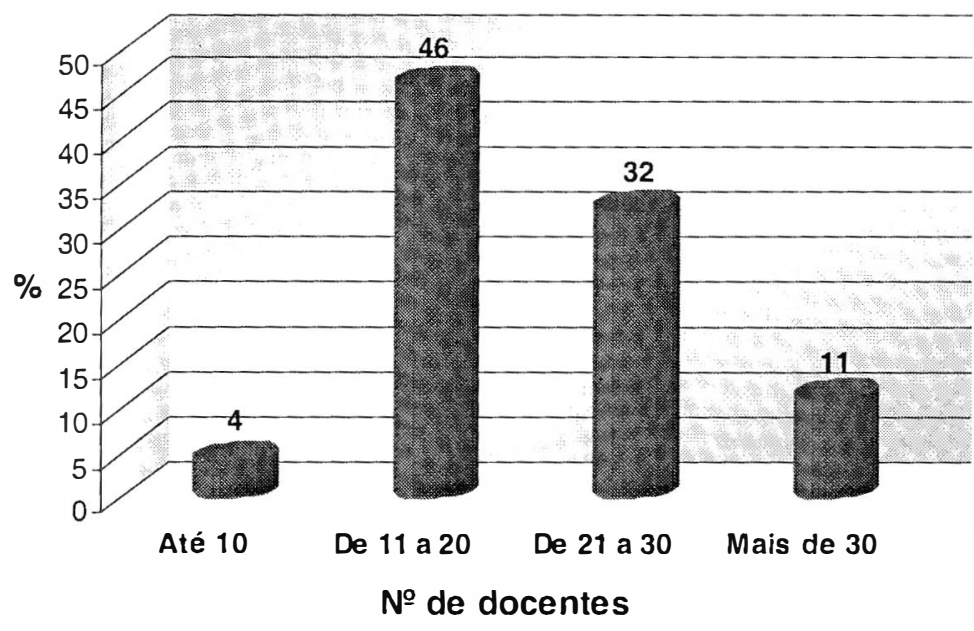

FIGURA 9 - DISTRIBUICÃO PORCENTUAL DO NÚMERO DE DOCENTES NOS DEPARTAMENTOS DE TURISMO/HOTELARIA

$14,3 \%$

$17,1 \%$

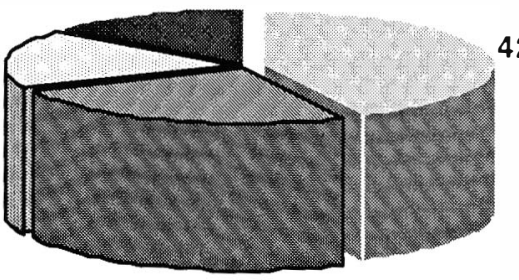

$42,9 \%$

A té $25 \%$

De 26 a $50 \%$

$\square$ De 51 a $75 \%$

$25,7 \%$

De $75 \%$ a $100 \%$

FIGURA 10 - DISTRIBUICAOOPORCENTUAL DOS DOCENTES COM EXPERIÊNCIA PRÁTICA NA ÁREA 
Ao analisar a qualificação do quadro docente dos cursos de turismo/ hotelaria, observa-se, na Figura 11, que o porcentual de professores com doutorado é relativamente baixo, pois $83 \%$ das instituições têm apenas até $25 \%$ do seu quadro com essa qualificação A situação é melhor em relação ao curso de mestrado, uma vez que em $40 \%$ das instituições, $26 \%$ a $50 \%$ dos docentes têm essa qualificação; e em $28,5 \%$ delas, $51 \%$ a $75 \%$ dos docentes têm esse diploma. Verifica-se também que $86 \%$ das instituições têm até $25 \%$ do seu quadro docente com professores graduados apenas e $59 \%$ com curso de especialização.

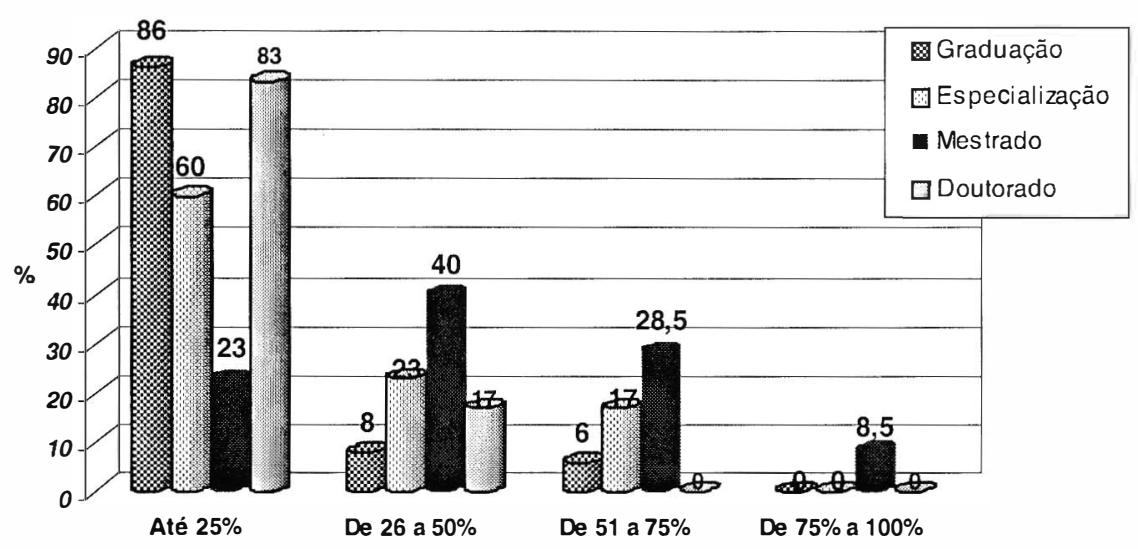

\section{FIGURA 11 - FREQÜÊNCIA DAS INSTITUIÇÕES PELO PORCENTUAL DE PROFESSORES QUE POSSUEM CURSO DE GRADUAÇÃO/MESTRADO/ ESPECIALIZAÇÃO E DOUTORADO}

Pode-se observar que poucos docentes tinham mestrado ou doutorado em turismo ou hotelaria. Dentre os cursos de doutorado citados, destacam-se a administração, geografia, história e sociologia. Dentre os de mestrado, a variedade é semelhante à da graduação, não havendo muitos mestres em turismo/hotelaria.

\section{Relacionamento com a Indústria}

Todas as instituições pesquisadas afirmam manter vínculos com organizações privadas ou públicas. A principal forma de relacionamento observadas entre as IES e as organizações privadas é o convênio para estágio, mas muitas outras formas podem ser realizadas como pode ser observado na tabela 6 .
TABELA 6 - DISTRIBUIÇÃO PORCENTUAL DAS FORMAS DE RELACIONAMENTO ENTRE AS IES E EMPRESAS

\begin{tabular}{l|c|c}
\hline \multicolumn{1}{c|}{ Formas } & $\begin{array}{c}\text { Frequééncia- } \\
\text { Absoluta }\end{array}$ & $\begin{array}{c}\text { Frequ̇éncia- } \\
\text { Relativa }\end{array}$ \\
\hline Convênio para estágio & 35 & 87,5 \\
Projetos/ consultoria/ cooperação técnica/ & 12 & 30,0 \\
contrato prestação de serviços & 9 & 22,5 \\
Pesquisas (de mercado/de campo) & 5 & 12,5 \\
Parceria & 2 & 5,05 \\
Treinamento & 1 & 2,5 \\
Convênio balcăo de empregos & 1 & 2,5 \\
Promoção de Eventos & 65 & \\
\hline TOTAL DE RESPOSTAS & 40 & 100,0 \\
\hline TOTAL DE RESPONDENTES
\end{tabular}

Obs.: A questão admitiu mais de uma resposta.

As freqüencias relativas foram calculadas com base no número de respondentes: 40 .

Entre as IES e as organizações públicas existem várias formas de relacionamento efetivadas através da participação das primeiras no Conselho Municipal de Turismo, no Comitê Estadual do Programa Nacional de Municipalização do Turismo (PNMT), na Secretaria de Estado do Turismo, Embratur, Centro de Estudos Avançados para o Turismo, além de convênios de estágio, treinamento, parcerias. Foram também mencionadas relações de parceria com organizações não-governamentais.

\section{Estágio}

Todas as IES pesquisadas oferecem estágio nos seus cursos de graduação. De forma geral, o estágio curricular é oferecido no último ano, tanto no último semestre como nos dois últimos, dependo da sua duração. Todavia, algumas instituições oferecem estágio extracurricular a partir do segundo ano e o curricular no sétimo e oitavo semestres. Foram mencionados também por alguns dos respondentes estágios noterceiro, no quarto, no quinto, no sexto e no sétimo semestres, mas sem especificar se eram curriculares ou extracurriculares. 
Quanto à duração do estágio, a resposta também foi variada, apesar de a maioria ter citado 300 horas, conforme estabelecido nas Propostas de Diretrizes Curriculares do MEC. Foi mencionado também estágio variando de 120 horas até 576 horas, de seis meses, um ano e até dois anos.

Em relação ao tipo de organização onde os estágios são realizados, verificouse que todos os respondentes mencionaram hotéis e organizações públicas. Observou-se que $85 \%$ encaminham seus alunos para empresas de transporte, $62 \%$ para restaurantes, $55 \%$ para agências de viagens e operadoras. Um número mais reduzido mencionou empresas de eventos, complexos turísticos, parques temáticos, empresas de lazer e entretenimento. Foram mencionados também centros de convenções, centros culturais, convention bureau, associações de classe, SENAC, SEBRAE, assessoria de treinamento, empresa de alimentação e organizações não-governamentais.

Existem problemas para a implementação e funcionamento de um programa de estágio eficiente, e muitos deles foram mencionados pelos participantes deste estudo. Os mais relevantes relacionam-se às empresas provedoras que, segundo os respondentes, não estão preparadas para supervisionar o estágio, adotando práticas inadequadas e utilizando os alunos como mão-de-obra barata. Além disso, as empresas foram criticadas por não remunerarem os alunos dignamente ou não cobrirem despesas de transporte e alimentação.

Outro problema refere-se às dificuldades dos próprios alunos para compatibilizarem os horários de trabalho com os de estágio, visto que a grande maioria trabalha para custear os próprios estudos

Existem também dificuldades advindas da falta de campo de estágio para acomodar o grande contingente de alunos. Finalmente, merecem citação os problemas decorrentes da dificuldades de supervisão que deveria ser oferecida pela escola, porque os professores, na sua maioria, trabalham sem dedicação exclusiva às instituições.

\section{Formaçāo de Empreendedores para as Pequenas Empresas}

Muitas universidades no Brasil têm sido sensíveis à demanda da comunidade para a criação de uma mentalidade empreendedora, trazendo novas perspectivas de trabalho para os alunos q

público ou na empresa privada. De forma geral, a oferta de cursos de formação de empreendedores tem sido feita pelos departamentos de administração, mas tem pernitido que alunos dos diversos cursos possam participar com disciplinas de caráter obrigatório ou optativo. Como muitos cursos de turismo/ hotelaria são voltados para aspectos gerenciais, procurou-se verificar até que ponto as instituições que os ofereciam estavam atentas a essa abordagem.
Verificou-se que cerca de $40 \%$ das instituições que participaram do estudo não oferecem, no momento, cursos voltados para a formação de empreendedores, mascerca de $10 \%$ delas demonstraram que têm intenção de oferecer como disciplina da graduação ou em curso de extensão. Cerca de 17,5\% das IES oferecem a disciplina "Novos Negócios/ Empreendedorismo" nos seus cursos de graduação, como obrigatória ou eletiva, ou discutem o seu conteúdo em disciplinas como "TópicosEmergentes". Também é ofertada em cursos de pós-graduação por $12,5 \%$ dos respondentes ou em cursos de extensão por $15 \%$. Alguns mencionam que vêm oferecendo esse curso em convênio com o SEBRAE. Merece destaque o comentário de um participante do estudo em relação ao envolvimento de sua instituição na formação de empreendedores:

Temos os maiores indices de criação de empresas do Brasil. A cada 50 alunos formados, 32 abrem empresas. Temos empreendedorismo no currículo, além da escola do empreendedor e da formaçào de líderes.

A exemplo das demais atividades econômicas, a maioria dos negócios do setor de turismoé realizada por empresas de pequeno porte. Um das questões dessa pesquisa sevoltou especificamente paraa existência de cursos voltados para o estudo das pequenas empresas. Verificou-se que apenas o porcentual de $22,5 \%$ fazem mençãoa algum tipo de ação que se volte para essas empresas. Um deles mencionou a existência dedisciplinas específicas: administração de pequenos hotéis e administração de agências. Alguns afirmam que o enfoque do curso é para administração tanto das grandes quanto das pequenas empresas. Outros mencionam esse tópico em cursos de aperfeiçoamento ou de extensão, em que um dos alvos são as pequenas empresas da região.

\section{Conclusōes}

Os cursos superiores em turismo/hotelaria no Brasil são muito recentes e o seu crescimento tem sido extraordinário nos últimos cinco anos. Esse fato resulta principalmente da abertura de novas instituições de ensino privadas e da percepção desses empresários de que o turismo é um fenômeno novo e de forte apelo entre os jovens. Praticamente todas essas novas instituições de ensino abriram cursos de turismo e, em menor número, de hotelaria. Como decorrência desse processo, percebe-se claramente que muitos cursos ainda não têm estrutura para funcionamento adequado, tampouco corpo docente com formação ou experiência na área. É visivel a ausência de titulação entre os docentes, sendo raros os que possuem mestrado ou doutorado em turismo hotelaria.

Embora os respondentes desse estudo afirmem, em função do aumento do número de alunos e da oferta de vagas, que a tendência para os cursos de turismo/ 
hotelaria é de crescimento, seria precipitado afirmar como isto ocorrerá. Uma das razões dessa incerteza reside na constatação de que muitas instituições de ensino privadas já começam a enfrentar problemas para preenchimento de suas vagas em muitos cursos, processo que poderá também ocorrer nos cursos de turismo/ hotelaria. A elaboração das Diretrizes Curriculares para os cursos pelo MEC é a sinalização de que os conteúdos de formação básica e específica estão sendo definidos através da discussão ampla dos especialistas no setor. A questão da qualidade dos cursos será muito mais enfatizada quando se iniciar a avaliação formal dos cursos pelo MEC, através do Exame Nacional de Cursos, o Provão, e da Avaliação das Condições de Oferta. As instituições privadas terão sua avaliação exposta ao público e serão solicitadas a investir na qualificação de seus quadros docentes, bibliotecas, computadores e outros equipamentos de apoio instrucional.

São muitos os desafios que os cursos de graduação em turismo/hotelaria deverão enfrentar para se consolidarem como área de conhecimento. Entre esses desafios, destacam-se a necessidade de docentes qualificados e a diminuição do "gap" entre as necessidades da indústria e o conteúdo dos cursos. As instituições de ensino superior devem dedicar maiores esforços na ampliação das suas relações com as empresas públicas e privadas e estar em sintonia com as mudanças no mercado. O estágio obrigatório terá de ser tratado como prioridade pelas IES, tanto pública como privada, e maiores recursos e esforços terão de ser investidos no planejamento e supervisão.

Este artigo pretendeu discutir de forma ampla os principais aspectos envolvidos na educação para o turismo, enfocando os cursos de graduação em turismo/ hotelaria no Brasil. Como estudo de caráter exploratório, pretendeu proporcionar visão geral sobre o tema, oferecendo a pesquisadores algumas idéias para futuras pesquisas. Entre essas pesquisas, pode-se mencionar a necessidade da oferta de novos cursos, o relacionamento com a indústria, a adoção de métodos inovadores para o ensino, o currículo e sua adequação regional, o estágio e a questão da qualidade. Cada um desses temas, por si só, dadas a sua profundidade e complexidade, merece ser objeto de estudos específicos. Cada um deles deve ser discutido de forma aberta pela comunidade acadêmica, procurando formas viáveis de operacionalização, buscando um modelo que se adapte à realidade de um país subdesenvolvido que tem na educação um dos seus maiores desafios.

\section{Referências Bibliográficas}

AMOAH, V., BAUM, T. 1997. Tourism education: policy versus practice. International Journal of Contemporan Hospitality Management, vol. 9, n.l, p. 5-12.

NSARAH, M. G. dos R.e REJOWSKI, M. 1994. Cursos superiores de turismo e hotelaria no Brasil. Turismo e Análise, São Paulo: ECA/USP, v.5, n. 1, p 116-128, maio.

BLANTON, D. 1981. Tourism training in developing countries - The social and cultural dimension In: ECHTNER, Charlotte M. 1995. Tourism education in developing nations a three pronjed approach. Tourism Recreation Research, v. XX. n.2, p. 32-41.

. ducation and the tourism industry: implications for tourism education. Tourism Recreation Research,v. 22, n. 1 .
COOPER, C., SHEPARD, R., WESTLAKE, J. 1994. Tourism and Hospitality E'ducation. England. The University of Surrey.

作 Research, V. XX, n.2, p. 32-41

ECHTNER, Charlotte M. 1995b. Entreprenetrial training in developing countries. Annals of Tourism Research, vol. 22 n. 1, P. 119-134.

Como elahorar projetos de pesquisa. 3. ed.São Paulo: Atlas.

. Tourism education for developing countries. Tourism Management, v. 8, n. 1, p 62 64.

LINTON N 1987. Trends in tourism and development: a third world perspective. Tourism Management, .8 , n. 2 june. REJOWSKI, M. 1996. Turismo e pesquisa cientifica. Sảo Paulo: Papirus.

TURISMOE HOTELARIA recrutam no pais todo 2001. Folha de S. Paulo, 27 maio de 2001. Empregos, p. E15. TRIGO, L. G. G. 1991. Cronologia do turismo no Brasil. Såo Paulo: CTI/TERRA.

\section{Recebido em 10/6/2001}

Aprovado em 4/8/200 